\title{
Abrangência e função da relação terapêutica na terapia comportamental
}

\author{
Therapeutic relationship scope and function \\ in behaviorial therapy
}

\author{
Gasparina Louredo de Bessa BRAGA
}

LUC VANDENBERGHE

\begin{abstract}
Resumo
Durante muito tempo os efeitos da terapia comportamental foram atribuídos à correta aplicação de técnicas para tratamento de transtornos específicos, sendo colocada em segundo plano a relação entre cliente e terapeuta. Tendências mais recentes vêm enfatizando as implicações diretas dos aspectos interpessoais do contexto terapêutico para a eficácia da terapia. Este trabalho propõe algumas reflexões práticas que permitem discutir o papel da relação terapêutica em duas funções básicas: como facilitadora da intervenção e como instrumento terapêutico em si. É proposta uma compreensão do relacionamento curativo como uma via de mão dupla na qual o terapeuta influencia o cliente por meio do impacto que o cliente tem sobre ele. É um tipo de relação da qual nem cliente nem terapeuta pode sair sem ser transformado.
\end{abstract}

Palavras-chave: psicoterapia analítica; terapeuta; terapia comportamental.

\begin{abstract}
The behavioral therapy results had been attributed for a long time to the right application of its techniques, giving sparse attention to the client-therapist relationship. More recent tendencies have emphasized that interpersonal aspects of the therapeutic context directly affect the therapy outcome. The present paper, reflecting on clinical practice, discusses two basic functions of the therapeutic relation: as a intervention and a therapeutic instrument itself. The curative relationship is analyzed as a two-way road where the therapist influences the client through the impact the client has on the therapist. Neither client nor therapist passes through this experience without being transformed.
\end{abstract}

Key words: analytical psychotherapy; therapist; behavior therapy.

Existe um entendimento do processo terapêutico como um conjunto deliberado de intervenções do terapeuta, sendo o resultado da terapia dependente das suas habilidades, e os fatores relevantes nesse processo a escolha correta das técnicas e o treino do terapeuta no seu manejo. Silveira e Kerbauy (2000) apontam que tal pressuposto levou uma geração de terapeutas comportamentais a referirem a si próprios com expressões do tipo 'engenheiros comportamentais', indicando uma atitude profissional estreitamente mecanicista.

\section{$\boldsymbol{\nabla} \mathbf{\nabla} \boldsymbol{\nabla}$}

1 Psicóloga, Consultório particular. Goiânia, GO, Brasil.E-mail:<euligab@ig.com.br>.

2 Professor Doutor, Departamento de Psicologia, Centro de Ciências Humanas, Universidade Católica de Goiás. Av. Universitária, 1410, St. Universitário, 74000-000, Goiânia, GO, Brasil. Correspondência para/Correspondence to: L. VANDENBERGHE. E-mail: <luc.vandenberghe@gmail.com>. 


\section{Terapia versus técnica}

Um dos momentos mais importantes no desenvolvimento da pesquisa empírica sobre a psicoterapia foi um artigo de Eysenck (1952) que documentou que simplesmente não havia indicações da eficácia dos tratamentos da época. Como eram derivados de teorias sem garantias de objetividade e na ausência de experimentos necessários para se obter resultados fidedignos, esse autor propôs uma alternativa às terapias, baseada no conhecimento científico em Psicologia.

Eysenck (1959) delineou duas vias de tratamento: procedimentos de extinção e processos de treinamento, e, para diferenciá-las das psicoterapias, as denominou de terapia comportamental. Atribuiu pouca importância para a relação interpessoal entre cliente e terapeuta. 0 psicólogo necessitava apenas ter habilidades para planejar e executar um programa comportamental. As teorias sobre a relação terapêutica não eram organizadas em postulados verificáveis e podiam ser desconsideradas. Com essas idéias de Eysenck, as décadas de 50 e 60, anos do pioneirismo da terapia comportamental clássica, constituem o auge do pensamento mecanicista no seio do movimento.

A partir da década de 70, procedimentos estatísticos sofisticados foram desenvolvidos visando esclarecer a eficácia das técnicas. Demonstraram uma equiparidade entre os métodos psicoterápicos mais diversos e freqüentemente também com tratamentos placebos (Luborsky et al., 2002). Esses dados apontaram que as técnicas não eram os únicos fatores relevantes e que havia necessidade de uma discussão acerca de outros fatores que interferem no processo terapêutico. Enquanto o estudo empírico dos fatores específicos (definidos como ações intencionais do terapeuta, a aplicação de procedimentos visando mudanças definidas) não perdeu sua importância (Chambless \& Ollendick, 2001), prestava-se cada vez mais atenção aos fatores inespecíficos, que são referentes a qualidades inerentes em uma relação humana construtiva, tais como auto-revelação mútua e aceitação. Essa evolução ficou conhecida como a 'virada relacional' na comunidade científica preocupada com questões empíricas referentes à eficácia da terapia (Norcross, 2002).

Eysenck (1994) evoluiu para um modelo de interação entre a aplicação de técnica e a relação terapêutica. Ele defendeu a idéia de que as variáveis inespecíficas (contexto interpessoal comum a diferentes abordagens terapêuticas) interagem com as variáveis específicas (técnicas), levando ao êxito da terapia. A relação terapêutica pode providenciar um contexto que torna eficazes as intervenções específicas, por revesti-las de credibilidade ou por evocar atitudes colaborativas ou pró-terapêuticas no cliente.

Esse amadurecimento contextualista é um complemento enriquecedor para o mecanicismo original de Eysenck. É coerente com a visão comportamental que acredita que os problemas psicológicos não são causados por fatores subjacentes, mas que são respostas adquiridas por meio da inserção do indivíduo no seu contexto. Tal visão constitui o fundamento para a compreensão da relação terapeuta-cliente no processo de mudança terapêutica.

Enquanto na terapia comportamental clássica (neopavloviana com uma visão altamente mecanicista), a relação terapêutica recebeu pouca consideração, as terapias da segunda geração, conhecidas como as cognitivo-comportamentais, enfatizaram a necessidade de construir uma relação terapêutica de natureza colaborativa, uma vez que esse é o contexto mais propício a uma terapia produtiva (Shinohara, 2000). A posição típica da terapia cognitivo-comportamental ao propósito da relação terapêutica, em consonância com as idéias de Eysenck, considera a importância de uma relação terapêutica que otimize a eficácia das técnicas usadas.

\section{A relação terapêutica em si}

A primeira onda da terapia comportamental incorporou uma revolta contra o subjetivismo e a ineficácia da psicoterapia. A segunda onda, com sua valorização do ser humano racional, era uma tentativa de complementar o modelo da terapia comportamental clássica, ressentida como muito mecanicista, porém preservando os ganhos da atitude objetiva e o foco técnico da primeira geração.

A terapia comportamental da terceira geração, geralmente referida como Análise Clínica do Comportamento (Kohlenberg, Tsai \& Dougher, 1993), tenta resgatar a subjetividade do cliente e do terapeuta no contexto da relação interpessoal que constitui o processo 
psicoterapêutico. A Functional Analytic Psychotherapy (FAP), desenvolvida por Kohlenberg e Tsai (1987), constitui-se uma proposta sistematizada do ponto de vista teórico e prático para análise da relação terapêutica. Tal proposta tornou-se um dos marcadores da Análise Clínica do Comportamento, colocando as variáveis acima chamadas de inespecíficas em primeiro plano no processo terapêutico. Essa abordagem supõe que o problema do cliente trazido para a terapia irá aparecer na relação terapêutica, podendo assim ser trabalhado ao vivo.

Os comportamentos ocorridos durante a sessão são classificados a fim de apontar classes funcionais constituídas dos problemas do cliente para facilitar a identificação de comportamentos clinicamente relevantes. Os comportamentos-alvo da psicoterapia são chamados de comportamentos clinicamente relevantes (CCR) e classificados da seguinte forma: CCR1 - comportamentos problemáticos que devem ser enfraquecidos ao longo da terapia uma vez que impossibilitam a ocorrência de repertórios efetivos; CCR2 - comportamentos que fazem parte do progresso do cliente ocorrido nas sessões de terapia, e que apresentam uma baixa probabilidade de ocorrerem no início do tratamento; CCR3 - interpretações que o próprio cliente faz de seu comportamento em relação ao terapeuta ou à situação terapêutica. Os CCR3 mais produtivos correspondem à aprendizagem da análise funcional pelo cliente.

O terapeuta observa CCR, constrói um ambiente terapêutico favorável à evocação de CCR, reforça os progressos, observa os efeitos potenciais do seu próprio comportamento em relação aos CCR do cliente e fornece interpretações de variáveis que afetam o comportamento do cliente (Kohlenberg \& Tsai, 2001). 0 terapeuta dessa abordagem escolhe táticas terapêuticas pelas contingências da relação suscitada entre ele (terapeuta) e seu cliente e não por sua orientação teórica, o que explica a integração de procedimentos oriundos de diferentes orientações teóricas.

Considerando que os comportamentos ocorrem devido às contingências de reforço experimentadas nos relacionamentos passados (de acordo com a história de aprendizagem do indivíduo), as mudanças terapêuticas também envolvem contingências de reforço que ocorrem no relacionamento entre o terapeuta e o cliente. É enfatizada a relação entre contexto e sentido. O cliente, o terapeuta e a relação entre os dois só serão compreendidos a partir do seu contexto. Do mesmo modo que essa abordagem busca explicação dos problemas comportamentais nas relações entre o indivíduo que se comporta e o meio ambiente no qual está inserido, acredita-se que as condições para tratar tais problemas também estejam nessas relações.

O termo 'tratar' ganha assim um novo sentido, mais afastado do modelo médico. Pois, como ressalta Banaco (1997), não há porque chamar um comportamento de patológico se todo comportamento é selecionado e mantido pelas relações que o indivíduo estabelece com seu ambiente, assim sendo, a resposta é sempre adaptativa. É incompatível com essa posição teórica a normatividade da saúde mental já que não está dentro do indivíduo, mas entre ele e seu ambiente, a causa de seu comportamento. Porém, faz-se necessário entrar em contato com a subjetividade do cliente porque a análise de seus sentimentos possibilita ao terapeuta levantar hipóteses sobre as contingências que afetam o comportamento do cliente, tanto dentro da sessão como em seu ambiente natural (Kolhenberg \& Tsai, 1987).

É reconhecida a dificuldade de se entender os eventos privados do cliente, sendo sempre um processo de inferência por parte do terapeuta, baseado na análise do comportamento verbal e na observação de respostas colaterais públicas que denotam estados emocionais. A FAP considera que demonstrações espontâneas de sentimentos ao que acontece durante a sessão - ou, com outras palavras, reagir emocionalmente nas sessões de psicoterapia - providenciam indicativos mais fidedignos de contato com variáveis importantes do que o relato verbal (Brandão, 2000). Assim sendo, a observação de sentimentos é pré-requisito básico para a compreensão da relação entre cliente e terapeuta.

O controle verbal sobre o comportamento, oriundo da análise racional, resolve muitos problemas, mas é fria e por isso tem um efeito de alienação. A mudança terapêutica profunda passa pela aprendizagem a partir de experiências reais na relação terapêutica. Se o cliente emite o comportamento problemático dentro do contexto da relação terapêutica é porque esta guarda uma similaridade funcional com o ambiente de sua vida diária. A história do cliente é descoberta e 
assuntos como confiança, valia ou dependência poderão ser conhecidos através do que acontece na relação terapêutica.

Segundo Banaco (1997), o que diferencia a relação terapêutica das relações do cotidiano é o que Skinner (1953) denomina de audiência não punitiva, na qual o terapeuta compreende os comportamentos do cliente sem julgá-lo, o que torna a relação terapêutica íntima. Intimidade diz respeito ao compartilhar de sentimentos, ao abrir-se para o outro. Surge quando as pessoas se comunicam abertamente, deixando claro o que pensam e o que querem, dividindo além do carinho, as experiências e os segredos, mostrando-se o que se é, mesmo nos medos, inseguranças e defeitos. 0 compartilhar de sofrimento e o compartilhar de sentimentos positivos de amor, proximidade, esperança, alegria e orgulho são indicativos da intimidade na relação.

Vandenberghe e Reis (2004) verificaram, em entrevistas com 20 ex-clientes de uma clínica-escola de psicologia, que a maioria dos participantes que vivenciaram a discussão na sessão sobre acontecimentos traumáticos com um envolvimento emocional fortíssimo teve uma melhora mais significativa do que qualquer um que relatou menor grau de envolvimento. Todos que relataram ter tido uma mudança ótima em suas vidas a partir da terapia relataram que tinham se envolvido de maneira muito intensa nesse trabalho. Porém, muitos clientes evitam revelar seus sentimentos porque foram punidos por isso no passado.

A FAP (Kohlenberg \& Tsai, 2001) utiliza o setting terapêutico para promover uma relação íntima de intensa troca e envolvimento. O terapeuta pode construir um clima de confiança, respeito e honestidade em que a revelação de sentimentos por parte do terapeuta pode abrir caminhos para o cliente. As emoções que são evocadas pela psicoterapia podem ser dolorosas. Portanto, o papel do terapeuta é bloquear a esquiva, até que essas respostas diminuam em intensidade. Se o cliente tolerar e tentar entender suas reações emocionais em vez de esquivar-se delas, é possível promover o desenvolvimento de outros repertórios pela possibilidade de ter contato com reforçadores distanciados até então pela evitação.

Entende-se que quando o trabalho de bloqueio da esquiva (mesmo tendo um efeito punitivo) é feito dentro de contexto relacional de intimidade, o cliente terá mais condições para suportar suas frustrações, tornando-se mais forte na sua condição de ser humano. De outro lado, o reforço natural na relação terapêutica - definido como a conseqüência que o próprio CCR2 do cliente causa quando é emitido -, sendo o mais próximo possível do comportamento (no tempo e no espaço), garante um maior efeito. As conseqüências naturais mais próximas, no caso, são os efeitos que o comportamento do cliente tem sobre a pessoa do terapeuta. Tais processos exigem que o terapeuta se permita ser afetado como pessoa pelo comportamento do cliente.

Partindo do pressuposto que a psicoterapia é um processo complexo que acontece em um contexto interpessoal no qual terapeuta e cliente interagem em um trabalho que visa uma transformação profunda, a pessoa do terapeuta não está ilesa no processo. Brandão (2000) aponta que ser psicoterapeuta é um exercício diário de crescer e fazer crescer. Da mesma forma que a relação terapêutica mexe com o cliente, o terapeuta também é tocado pela relação. Sendo a relação terapêutica uma contingência de determinação recíproca, a atenção do terapeuta deverá também estar dirigida aos seus próprios sentimentos. Isto é, aos sentimentos que o cliente provoca nele.

Como comenta Zamignani (2000), o cliente é o ambiente imediato do terapeuta, que seleciona e mantém parte de seu repertório. Banaco (1993) enfatiza a importância de discriminação de emoções como raiva, ansiedade, pena, admiração e inveja que podem aparecer durante a sessão. Os sentimentos do terapeuta dão pistas para se compreender as contingências que atuam na relação. Na FAP (Kohlenberg \& Tsai, 2001), a análise funcional das emoções evocadas pelo comportamento do cliente é uma das principais estratégias para ter acesso às contingências relevantes da sua vida e pode ajudar diretamente na conscientização do cliente sobre o impacto que seus comportamentos têm sobre as pessoas com quem interage.

Considerando esse leque de possibilidades, o presente trabalho teve como objetivo ilustrar a diversidade de funções que a relação terapêutica pode ter, traçando assim algo do campo que a relação terapêutica ocupa na terapia comportamental. 


\section{Método}

\section{Participantes}

São discutidos dados provenientes de três clientes atendidas pela primeira autora no sistema de terapia individual e de co-terapia, tendo, nesse último, dois terapeutas estagiários atendido alternadamente, enquanto um assumia o lugar de terapeuta, o outro ficava como co-terapeuta.

As clientes são sra. "A", de 48 anos, casada e mãe de duas filhas adolescentes, auxiliar de escritório; sra. "B", de 22 anos, solteira, auxiliar de contabilidade, com formação superior incompleta, e sra. " $C$ ", de 33 anos, casada pela terceira vez, mãe de dois filhos adolescentes, com formação superior incompleta.

\section{Procedimentos}

Transcrições de diálogos de sessões terapêuticas foram selecionadas para ilustrarem diferentes papéis da relação terapêutica durante esses três tratamentos e são apresentadas e comentadas a seguir.

\section{Resultados}

\section{Relação terapêutica como:}

\section{1) Contexto facilitador da intervenção}

O papel da relação terapêutica não punitiva no sentido apontado por Skinner (1953) pode ser ilustrado por falas das clientes. Trata-se de uma relação que viabiliza uma crescente vivência de reações emocionais fortes entre cliente e terapeuta."Aqui me sinto à vontade para falar de meus problemas, falo de coisas que nunca tive coragem de contar para ninguém," ou"É interessante, aqui falo coisas que tenho vergonha até de mim mesma...."

Senhora "A"raramente conseguia expressar seus sentimentos e quando os expressava era pouca assertiva. Tal dificuldade estava relacionada com sua história de vida (abandono pelos pais e criação repressiva pela tia que a adotou) e causava problemas em todos os setores de sua vida cotidiana. No contexto clínico ela se comportava de forma similar; nas primeiras sessões não conseguia falar de seus reais problemas e se recusava a fazer as tarefas. Após várias sessões em que aparecia sem ter feito as tarefas, a terapeuta comentou a dificuldade e a sra." A" respondeu: "Eu não gosto de fazer isto" (demonstrando impaciência e esfregando uma mão na outra). A terapeuta repetiu: "Não gosta?" (olhando para a cliente e sorrindo em um gesto de aceitação). Quando a cliente responde: "Eu acho difícil escrever" a terapeuta diz: "É, escrever não éfácil mesmo. Eu também tenho muita dificuldade com escrita. Quando escrevemos nos expomos para os outros e deixamos registrada a nossa marca. Às vezes é difícil para mim revelar para os outros quem eu sou ..." (terapeuta se vulnerabilizou).

Cliente: "Fico pensando que o queeuescrever não vaiter sentido para vocês".

Nesse momento a cliente compartilhou o que sentia (CCR2), mostrou que sua dificuldade era entrar em contato com o estímulo aversivo - sentir-se inútil, sem sentido, rejeitada e, portanto, novamente mal amada. A terapeuta afirmou que qualquer coisa que ela escrevesse ajudaria muito no andamento do trabalho. Após várias sessões em que a terapeuta mostrou cuidados e contato corporal, a cliente passou a trazer tarefas, cujos conteúdos possibilitaram à terapeuta gradativamente encorajar a cliente a entrar em contato com as recordações dolorosas de abandono e maus tratos que tanto queria "apagar de sua vida".

\section{2) Estratégia de intervenção em si}

Senhora "B" apresentava dificuldade em manter relacionamentos amorosos, queixava-se que sempre todos a abandonavam logo nos primeiros meses, e que só se aproximavam dela por questões sexuais. Durante as sessões terapêuticas falava sem parar, respondia questões indo além das perguntas (contando histórias longas), mudava espontaneamente de assunto, dificultando as intervenções da terapeuta.

No final das sessões a terapeuta sentia-se cansada e irritada. A atenção a esse sentimento levou a terapeuta a orientar a cliente a observar seu comportamento enquanto estava com as pessoas, o conteúdo de seus assuntos e o impacto que causava. Em uma sessão posterior, a cliente falou: "Você me pediu para observar meu comportamento, notei que falo muito, lá em casa todos falam muito e ao mesmo tempo...". Contou uma 
infinidade de histórias, mudando de assunto, fugindo da atividade proposta. Isto é, manteve o padrão comportamental (CCR1) mesmo após entender o problema, e a terapeuta perguntou:"Será que este falar muito que você descreveu acontece da mesma forma que está acontecendo agora comigo?" A cliente olha assustada e sorri: "É, eu falo muito aqui também, né". Terapeuta: "Você começou a responder, mas logo mudou de assunto, falou um monte de coisas, interessantes mas que não estavam dentro do assunto proposto; tentei sinalizar, dar pistas, mas vocênão ol hava para min, em meu rosto, em meus olhos." Cliente: "Éas vezes não dou muita atenção para as pessoas..." Terapeuta: "Agora que estamos refletindo o efeito de seu comportamento, o que acha que eu estava sentindo enquanto falava?" (uso da relação terapêutica). Cliente: "Acho que estava enjoada de meverfalar".Terapeuta: "Verdade, não senti prazer. Fiquei cansada. Deu até vontade de não estar aqui. Será que este comportamento seu causa esta mesma sensação nas outras pessoas com que convive lá fora?" (terapeuta compartilhou os efeitos que a cliente tem sobre ela e ofereceu uma interpretação)....

Cliente (meio que paralisada): "Acho que sim, esse pode ser um dos motivos (pensa). Uma vez eu e o [X] conversávamos e por um momento ele pôs a mão no ouvido e saiu sem dar atenção, fiquei sem entender, achei que não gostava de mim...."

Compartilhando seus sentimentos, a terapeuta possibilitou à cliente vivenciar sentimentos de rejeição como conseqüência do seu comportamento. Precisava de uma vivência intensa e genuína, ao vivo, dentro de uma relação verdadeira para a cliente entender seu impacto sobre os outros.

\section{3) Via de mão dupla}

Sra. "C" havia tido vários relacionamentos amorosos infundados. Sempre era ela quem os finalizava, sofria muito e logo se envolvia em outra relação.

Na sessão terapêutica a cliente se comportava de modo ambivalente, queixava-se de sentimento de inadequação, solidão, vazio, medo. Apresentava discurso vanglorioso, estava sempre tentando humilhar a terapeuta, usava roupas extravagantes e sedutoras, deixava claro que estava ali mais para ajudar as terapeutas e afirmava que as pessoas com quem convivia sempre se apaixonavam por ela, inclusive as do sexo feminino. Já havia passado por vários trata- mentos psiquiátricos e psicoterapêuticos, sempre os abandonava e culpava os profissionais (de assédio sexual, incompetência ou desequilíbrio).

A cliente atrasava e faltava muito. O processo terapêutico não evoluía. Veio o período das férias e ela não compareceu para a sessão de encerramento. A terapeuta ligou deixando recado, mas não houve retorno; aguardou algum tempo, depois ligou convidando-a a comparecer. A cliente demonstrou querer muito continuar com a terapia, declarava estar sofrendo. A terapeuta então questionou: "Pensei que não queria mais fazer terapia, que não estivesse gostando, você não veio na sessão de encerramento do semestre, não ligou como havíamos combinado, me sentiatéincomodada em estar ligando para você..." (terapeuta compartilhou sentimentos): Cliente: "Fiquei pensando que vocês não queriam mais me atender." (CCR2: expôs sua vulnerabilidade). Terapeuta: "O que foi feito para que pensasse assim?". Cliente: "Não sei, achei que tinha cansado de mim, que ia me abandonar."Terapeuta: "Vocêpensou que eu iria te abandonar e me abandonou primeiro." Cliente: "É, acho que foi isso".

Terapeuta: "Isto acontece com muita freqüência. É assim que você reage em seus outros relacionamentos?". Cliente: "Sim, com todos. Sofro muito e acabo sempre me distanciando das pessoas. Não sei pedir ajuda" Terapeuta: "O queépedir ajuda?". Cliente: "Éserhumilhada".Terapeuta: "É, deve ser muito difícil pedir ajuda para mim, uma terapeuta que ainda é só uma estagiária, não inspira muita confiança e que, como você mesma fez questão de deixar claro em algumas sessões, está precisando de ajuda tanto quanto você" (terapeuta se vulnerabilizou). Cliente (chorando): "Na verdade não éisto. Acho que todos vão me abandonar e meu mundo vai desabar". Terapeuta: "Então parece que funciona assim, para não entrar em contato com este sentimento, se comporta de forma contrária, usa um discurso elaborado se vangloriando; tenta humilhar as pessoas e quando pensa que elas podem te abandonar, foge delas" (compartilhou a análise funcional). Cliente (chorando muito): "Gostaria que me dissesse o que fazer para não me sentir assim" (depositou confiança na terapeuta - CCR2). Terapeuta: "Não existe receita pronta, podemos tentar encontrar algumas saídas juntas, acho que você começou bem tomando consciência destas questões, mas é necessário ter clareza que agindo desta forma você provoca o afastamento real das pessoas, como 
já estava acontecendo comigo..." (terapeuta validou comportamento e interpretou).

A partir deste momento, houve mais envolvimento e entrega de ambos os lados. Uma semana posterior a cliente ligou:"Esta semana estou com muitos problemas, preciso de sua ajuda, seria possível fazer uma sessão extra comigo?" (CCR 2). Esta experiência possibilitou à terapeuta compreender o impacto de seus sentimentos na relação terapêutica. A forma da cliente se comportar na sessão provocou na terapeuta uma rejeição (velada) que aos poucos foi se configurando em um quadro relacional funcionalmente parecido como a situação vivida pela cliente com seus pais - "... acho que gosto deles, mas ao mesmo tempo sinto ódio por eles. ... ela dizia que me amava, mas nunca me botava no colo, nunca me fez um afago, ... Meupai me colocava no colo, mas falava: sua avó não presta, é suicida, sua mãe é igual a ela e você é igual a sua mãe." Neste contexto de ambivalência e invalidação de sentimentos a cliente desenvolveu táticas de vida disfuncionais. A relação terapêutica evocava esses comportamentos, uma vez que a terapeuta falava que queria ajudar a cliente, mas a sentia como uma ameaça e se mantinha numa posição de defesa, afastada com receio de que ela pudesse lhe prejudicar profissionalmente.

Ter vivenciado a situação de ambivalência no contexto clínico fez eclodir sentimentos negativos na cliente e na terapeuta. A análise funcional da relação terapêutica estabelecida até aquele momento viabilizou reflexões, revisão de sentimentos e de estratégias terapêuticas. Entendeu-se que para que a terapeuta pudesse continuar ajudando, teria que se vulnerabilizar e se deixar ser tocada pela cliente, em vez de fugir do efeito aversivo do comportamento da cliente sobre ela. A reflexão sobre seus sentimentos em relação à cliente possibilitou à terapeuta entrar em contato e trabalhar suas próprias dificuldades de enfrentamento de seus medos.

\section{Considerações Finais}

A FAP propõe o entendimento de que o efeito da terapia é resultado do que ocorre dentro da relação terapêutica. Ao deparar-se com o sofrimento'real'e único de cada cliente, bem como com a confiança depositada, muitos sentimentos, lembranças e reverências são evocados na terapeuta. Esse contexto emocional afeta a relação terapêutica. A conscientização, a aceitação e, por que não?, o compartilhar dessas emoções com os clientes viabilizam um processo de determinação recíproca, no qual terapeuta e cliente são mutuamente tocados pelos efeitos da interação e possibilitam uma aceitação genuína, ao mesmo tempo mobilizando movimentos de inquietude e busca pela mudança e pelo saber frente ao inusitado.

A relação terapêutica, além de um lugar de colaboração, um contexto favorecedor e propício para a aplicação de intervenções terapêuticas, como foi destacado no fragmento de sessão com a sra. "A", constituiu-se um instrumento privilegiado de intervenção que provocou mudanças na vida de ambos os envolvidos na relação, como pode ser percebido nos fragmentos de sessão com as sras. "B" e "C". Ficou claro que para poder ajudar seus clientes, o terapeuta precisa antes de tudo envolver-se com eles numa relação de aceitação; precisa se deixar tocar pelos clientes; precisa se deixar mudar para mudar os clientes. A análise funcional dos sentimentos envolvidos na relação com a sra. "C" mostrou, de maneira mais aguda, como uma relação que deixa a terapeuta intocada poderia ter sido ineficaz para a cliente, independentemente de qualquer técnica ou manejo terapêutico adotado.

\section{Referências}

Banaco, R. A. (1993). O impacto do atendimento sobre a pessoa do terapeuta. Temas em Psicologia, 2 (1), 71-79.

Banaco, R. A. (1997). Tendências neo-behavioristas da terapia comportamental: uma análise sobre a relação terapêutica. Anais do Encontro sobre Psicologia Clínica (pp.47-52). São Paulo: Universidade Mackenzi.

Brandão, M. Z. S. (2000). Os sentimentos na intervenção terapeuta-cliente como recurso para a análise clínica. In R. R. Kerbauy (Org.), Sobre comportamento e cognição (Vol. 5, pp.24-29). Santo André: ESETec.

Chambless, D. L., \& Ollendick, T. H. (2001). Empirically supported psychological interventions: Controversies and evidence. Annual Review of Psychology, 52 (1), 685-716.

Eysenck, H. J. (1952). The effects of psychotherapy evaluation. Journal of Counseling Psychology, 16 (3), 319-324.

Eysenck, H. J. (1959). Learning theory and behavior therapy. Journal of Mental Science, 105 (1), 61-75. 
Eysenck, H. J. (1994). The outcome problem in psychotherapy: what have we learned? Behavior Research and Therapy, 32 (5), 477-495.

Kohlenberg, R. J., \& Tsai, M. (1987). Functional analytic psychotherapy. In N. S. Jacobson (Org.), Psychotherapists in clinical practice: cognitive and behavioral perspectives (pp.388-443). New York: Guilford Press.

Kohlenberg, R. J., \& Tsai, M. (2001). Psicoterapia analítica funcional: criando relações intensas e curativas. Santo André: ESETec.

Kohlenberg, R. J., Tsai, M., \& Dougher, M. (1993). The dimensions of clinical behavior analysis. The Behavior Analyst, 16 (2), 271-282.

Luborsky, L., Rosenthal, R., Diguer, L., Andrusyna, T. P., Berman, J. S., Levitt, J. T., Seligman, D. A., \& Krausse, E. D. (2002). The dodo bird verdict is alive and well - mostly. Clinical Psychology: Science and Practice, 9 (1), 2-12.

Norcross, J. (2002). Psychotherapy relationships that work: therapist contributions and responsiveness to patients. Oxford: Oxford Press.
Shinohara, H. (2000). Relação terapêutica: o que sabemos sobre ela? In R. R. Kerbauy (Org.), Sobre comportamento e cognição (Vol. 5, pp.229-233). Santo André: ESETec.

Silveira, J. M., \& Kerbauy, R. R. (2000). A interação terapêutica: uma investigação com base na queixa clínica. In Sobre comportamento e cognição (Vol. 5, pp.213-221). Santo André: ESETec.

Skinner, B. F. (1953). Science and human behavior. New York: MacMillan.

Vandenberghe, L., \& Reis, L. A. (2004). Terapia comportamental: o efeito da integridade do tratamento de acordo com a perspectiva do cliente. Estudos, 32 (Esp.), 205-218.

Zamignami, D. R. (2000). O caso clínico e a pessoa do terapeuta. In R. R. Kerbauy (Org.), Sobre comportamento e cognição (Vol. 5, pp.234-243). Santo André: ESETec.

Recebido em: 12/5/2005

Versão final reapresentada em: 1/11/2005

Aprovado em: 5/12/2005 